\title{
Exploring User-Centred Design in Practice: Some Caveats
}

\author{
Patrizia Marti • Liam J. Bannon
}

Received: 10 November 2008 / Accepted: 3 February 2009/Published online: 3 March 2009

(C) Springer Science + Business Media B.V. 2009

\begin{abstract}
This paper provides a nuanced perspective on the topic of user-centred design (UCD) in the humancomputer interaction (HCI) field. After a brief outline of its emergence, we describe some of the central tenets of the approach, using the process model of Gulliksen et al. (Behav Inf Technol 22(6):397-409, 2003) as a welldocumented exemplar. We then examine in more detail some of the difficulties one can encounter in performing user-centred design (UCD), illuminating these issues through vignettes from specific projects in which we have been involved. In this paper, we focus on issues that can arise in working with children and with people of differing mental abilities. Our argument is that, while a user-centred perspective is required at all times in the design team, the forms of participation of users in the design process needs to fit the context and can vary significantly from that presented as the prototypical UCD approach.
\end{abstract}

Keywords UCD · Users forms of participation . Children $\cdot$ Impaired people

\section{P. Marti $(\bowtie)$}

Communication Science Department, University of Siena, Siena, Italy

e-mail: marti@unisi.it

L. J. Bannon

Interaction Design Centre, University of Limerick, Limerick, Ireland

e-mail: Liam.bannon@ul.ie

\section{Introduction}

This paper examines aspects of the user-centred design (UCD) model currently in vogue and discusses some of the issues involved through practical design cases. One of the aims of this paper is to encourage further discussion on the variety of ways in which designers can work on interdisciplinary design teams and the different ways in which "user involvement" can be managed across the different phases of the design cycle.

For students today who study the field of humancomputer interaction (HCI) in computing or psychology courses worldwide, the notion of "user-centred design" has become a mantra. The term emerged in the early 1980s, sometimes in slightly different formsuser-centred system design (UCSD), user-centred design (UCD) - and implied an up-front commitment to taking the needs of the user as the central point for design. The psychologist, Donald Norman, is associated with the term "user-centred system design" (UCSD), as he was a joint editor of a collection of papers from the humanmachine interaction project at the University of California, San Diego in the early 1980s with this title (Norman and Draper 1986).

Note that, while the UCD or UCSD terms serve as an important correction to other design approaches, which tend to ignore the human side of things, this did not imply that the users were necessarily seen at this time as active participants in the design process 
itself. Rather, as in (cognitive) psychological experiments, users were to be studied, questioned, observed, and their performance on tasks measured.

A more radical approach to user participation in design was emerging within the systems development field among a group of Scandinavian researchers. This "collective resource" model emerged from the work of people such as Nygaard, Ehn, Bodker, and Kyng in the early 1980s in the context of projects on the democratisation of working life. It is often commonly labelled, somewhat loosely, as the "Scandinavian model". Here, users are seen as equal partners in the development of systems (see the papers in Bjerknes et al. 1987). This perspective takes the work process as primary and attempts to support workers through providing them with skill-enhancing computerised tools (see Ehn and Kyng 1987). What is required are various methods for envisioning future work situations, so users can, in (hypothetical) use, discover potential problems and make suggestions as to how to re-design the planned system. This involves intense commitment on the part of both users and designers to acknowledge each others competencies and inadequacies and to attempt to construct a mutual dialogue.

The reason for discussing this systems development work in a paper on HCI is that this work began to influence and inform HCI in the early 1980s. This alternative approach would imply moving a step beyond a user-centered view to a user-involved view. Here, users are not simply viewed as objects of study but as active agents within the design process itself. Thus, user involvement is not simply required to increase the effectiveness of the resulting system but also to develop a more democratic work situation, so those who will be affected by change have an influence on the kind of changes that will be made ${ }^{1}$. Its influence within HCI has been to further explore a variety of methods of involving users at all stages in the design process. It moves us away from simple user surveys or interviews and evaluations towards more active engagement in exploring the design space, experimenting with prototypes, etc.

\footnotetext{
${ }^{1}$ In later years, the term "Cooperative Design" has come into use (Greenbaum \& Kyng, 1991) which, while preserving an interest in methods of user involvement, reduces somewhat the overly political agenda evident in the earlier collective resource model.
}

\section{The UCD Approach}

During the 1990s, the main features of a UCD approach became more clearly defined. This section provides a brief outline of a prototypical UCD approach, utilising the framework presented in a detailed yet concise paper by Gulliksen at al. (2003). This approach builds on a number of earlier attempts to elucidate key features of a user-centred approach, such as the work of Gould and colleagues on ensuring usability (Gould and Lewis 1985; Gould et al. 1997). The framework also builds on the general principles of ISO Standard 13407, Human-centred design processes for interactive systems (ISO 13407 1999), which enshrines the user-centred process approach in an industry standard. Gulliksen's framework outlines 12 principles for successful user-centred system design, based on a large body of field work and practical action-oriented systems development projects. These are enumerated briefly below (from Gulliksen et al. 2003):

1. "User focus (Gould et al. 1997, ISO 13407 1999)

2. Active user involvement (Nielsen 1993; Gould et al. 1997; ISO 13407 1999)

3. Evolutionary systems development - the systems development should be both iterative and incremental (Boehm 1988, Gould et al. 1997)

4. Simple design representations (Kyng 1995)

5. Prototyping (Nielsen 1993; Gould et al. 1997)

6. Evaluate use in context (Nielsen 1993; Gould et al. 1997)

7. Explicit and conscious design activities (Cooper 1999)

8. A professional attitude (ISO 13407 1999)

9. Usability champion - usability experts should be involved early and continuously throughout the development lifecycle (Kapor 1990)

10. Holistic design - all aspects that influence the future use situation should be developed in parallel (Gould et al. 1997)

11. Processes customization - the UCSD process must be specified, adapted and/or implemented locally in each organisation.

12. A user-centred attitude should always be established." (Gulliksen et al. 2003)

Given that there seems to be near consensus on the importance of UCD and on the ways in which it can be achieved, it might appear that we can close 
the book on the topic. However, things are not quite so straightforward, as we shall see in subsequent sections. Especially the exact ways in which users can participate in the design process and the stages in the design where they should be involved are often contentious issues. We highlight some of these issues in the context of attempting to apply a usercentred approach in projects where we are dealing with user groups who present a rather special set of circumstances - namely when working with children and with people with very different sets of mental abilities.

\section{Case 1: Children-Centred Design: Varying Forms of Participation-Testers, Informants and Design Partners}

Applying UCD approaches with children raises a number of issues. Alison Druin has written extensively on this subject, as an advocate of the benefits of participative design with children, and promotes a very open and participative approach where children can engage in virtually all facets of the design process. Druin (1998) defines four roles that children can play in the technology design process: user, tester, informant or design partner. She views children as users when they contribute to the research and development process by using technology, while adults observe and videotape with the aim of testing concepts and understanding the learning process. Children are testers when they try out prototypes of emerging technologies. The goal of this type of research is to shape new technologies before commercial products or research projects are released. Informants contribute at various stages of the design process mainly being by being asked for their opinions when researchers feel that children could provide needed information. Design partners are equal stakeholders in the design of new technologies. While children do not have the same specialised expertise that adults have, they have equal opportunity to contribute in any way they can to the design process. In her later writings, Druin strongly pushes for treating children as equal partners in design projects.

Scaife et al. (1997) also advocate a role for children in the design process but emphasise that the role of the child (user) may differ markedly in different projects and even within different aspects of the design process. They view children as native informants, a term that denotes the value of seeking a view from within the culture while still attempting to go beyond it to form more general theories. In this approach, children are involved in the design process through interviews, researchers probing them about their understanding of some specific concepts, asking them to explore the concepts, comparing abstract representations and real events, encouraging them to develop ideas about the future system and trying out mock-ups and low-fidelity prototypes. Even if the approach has proven successful in terms of suggestions and ideas developed by the children, however, the designers reported some difficulties in involving the children as native informants. Firstly, not all children are able or willing to be creative designers or even informants about current practices since talking with unfamiliar adults, in a school context, can be a significant inhibitor. Other difficulties are related to the management of the process - when and how to intervene and remain within the project vision.

Similar difficulties were observed in our development work on POGO (Rizzo et al. 2003), a real/virtual environment for supporting the unfolding of narrative competence in children of 6-8 years (primary school), where children create, explore and develop narrative language and social skills. Even if in the project children and teachers were constantly involved in the process (e.g., definition of pedagogical objectives, observation of practices related to the use of narratives in the school, definition of user requirements, development of scenarios, mock-ups and testing), a number of problems have been experienced. First of all, the teachers found it difficult to comprehend the potential of ubiquitous technologies to support storytelling. Even if they proved to be extremely creative in the classroom - involving children in narrative activitiesthey showed limited skills in envisioning new scenarios of use with ubiquitous technologies. On the other hand, children were extremely creative when involved in the assessment of early prototypes and enjoyed Wizard of $\mathrm{Oz}$ sessions (Erdmann and Neal 1971). However, without the support of external representations of the final system, they became less and less focused on the design activities, preferring to play with their friends.

For these reasons, the fundamental concept development was the prerogative of professional designers from Philips Design and Domus Academy. Partly inspired by user observations, designers produced 14 
visions of narrative environments (Domus Academy 1999). These design concepts represented different ways in which technologies could facilitate narrative processes and mediate the development of children's communication. Only after this stage of the process were the different participants in the project (researchers, children, teachers and technology developers) asked to evaluate the design concepts. This evaluation was performed firstly by filtering the concepts through the defined pedagogical objectives proposed by the teachers and, secondly, through the comments of the teachers. This was an effective way to allow different stakeholders, such as teachers, social scientists, interaction and industrial designers, to join the design process and to promote the mutual awareness of theoretical issues and pedagogical and design practices. Children were involved later in the process, to refine the concepts, explore and test existing mock-ups and build new ones. The prototyping phase was carried out through Wizard of $\mathrm{Oz}$ testing sessions in the school. This method allowed user requirements and design concepts to be explored at an early stage in the design process. Teachers and children performed narrative activities using the available prototypes in iterative sessions, and the testing results were used to improve the prototypes until the final system was developed.

Some lessons were learned from the POGO project concerning children-centred design. First of all, working with a multifaceted design team composed of a number of professional designers tended to postpone the involvement of the children in the process, and collaboration with them was focused on specific phases like requirement elicitation, scenario definition and iterative assessment. This strategy meant that users did not experience a sense of inadequacy in fully comprehending the role of ubiquitous technologies in supporting narrative activities at the school. However, the children were still actively involved in the process. They created new narrative contents - re-combining elements of different stories in novel and unexpected ways, using the POGO tools in surprising ways. For example, the Beamer tool was extensively used to scan and acquire their own image so that they could become characters in the story (see Fig. 1b). Most of the tools were actually redefined and refined by the children. The designers mainly incorporated suggestions and practices that the children developed using POGO into newer and richer generations of the system.
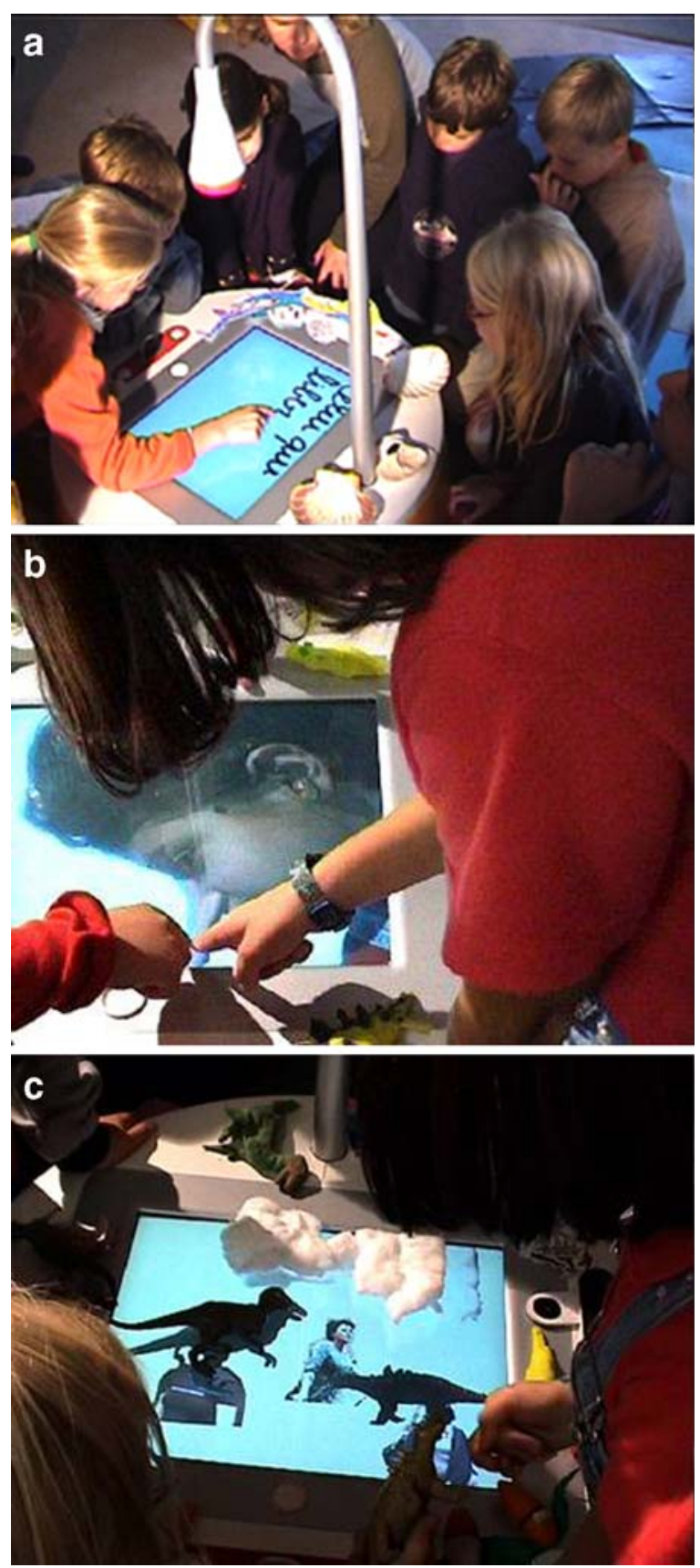

Fig. 1 a Children writing the title of their story on the Beamer; b child morphing her own image on the Beamer; c Children composing on the Beamer a background with cotton used as clouds

The experience of POGO also showed that 'lowtech' and 'lightweight' communicative and creative tools are particularly well-suited for children-centred design. They allow for collaborative building of 
mock-ups and co-constructing rapid prototypes, skills that children usually like to develop and practice. Thus, we see that user-centred and even user-involved design needs to be developed with a sensitivity to the work environment, the ages and skills of the users and mesh with the particular phase of the design process in which we are at any moment engaged. In sum, we see different users/informants as shaping the design at different stages: at the beginning, to help designers problematise the domain; in the middle, to test out and reflect on assumptions, and at the end, to evaluate prototypes in real-world contexts.

\section{Case 2: Working with Dementia Carers and Patients}

There are situations where user involvement in the design process may be very difficult to achieve and may even be undesirable. Domains like health care or rehabilitation are illuminating examples in this respect. The impairments of the users may limit the degree to which they can collaborate or express themselves appropriately, and external intervention, unless very carefully and sensitively managed, can produce irritation, or even fear, alarm, and anger. Design activities involving users of differing abilities can run the risk of confusing a specific, situated experience with a more systematic understanding of the problem space, thus leading to a potentially incorrect interpretation of real user needs. Furthermore, apart from important ethical issues concerning the development, deployment and evaluation of systems in such settings, methods for eliciting needs in such a complex setting are relatively under-developed. For example, direct observation of people in these contexts is regarded as not merely difficult but is often inappropriate and intrusive (Crabtree et al. 2003).

As a concrete example of this difficulty, we report in this paper a case study on the development of digital technologies for the treatment of dementia-affected patients. Dementia subjects suffer from an acquired permanent neurodegenerative disorder that affects the global functioning of the individual, progressively impairing cognition, personality and behaviour. In particular, dementia is strongly characterised by social isolation and difficulties in communication. Speech becomes increasingly inefficient, and progressive short-term memory difficulties and problems with new learning make conversations and other social interactions problematic (Ripich et al. 1991). Consequently, most people become reliant on caregivers to initiate engagement and interaction and to take care of everyday living activities and arrangements. The social sphere of the individual is jeopardised not only by the impairment of social abilities resulting from global functional impairment of the subject but also by the patients withdrawal from social interaction due to a number of contextual factors ranging from aural and visual ability impairment, institutionalisation and interpersonal disorientation, lack of self-esteem and low motivation (Marti and Giusti 2008).

Very early in the design, process we realised that directly involving such people in active participatory design processes would be inappropriate and unethical, as well as of little utility - as debate, interaction and negotiation were frustrating and inappropriate activities for them. The methodological response we adopted to face this problem took a number of forms. First of all, we turned our attention to a "light observation" of their everyday life practices, putting most of our effort into participatory design with therapists combined with an analysis of relevant literature and modelling techniques to feed the conceptual design. The observation resulted in a very naturalistic approach where we only used our senses, intuition and paid respect to the privacy of the Home Care guests. Quite soon, we were struck by the behavioural response of these people to simple external stimuli. Very basic sensory-motor patterns like grasping, rolling and pulling recurred in many of their activities; memories were stimulated by natural and unstructured stimuli like smells, lights and moving objects, so we used this simple observation to start developing design concepts.

We also had extensive discussions and interaction with the other people surrounding the patientsnamely therapists, care givers and, on occasion, family members and associates. Thus, we extended the concept of UCD to encompass not just the designer-user direct relation but taking in the ecology of the environment where we were working, in all its complexity and richness.

An extensive analysis of the residual abilities of the elderly was conducted to define a framework for understanding the progressive manifestation of $\operatorname{cog}$ nitive and behavioural symptoms. Even if the degree and the temporal manifestation of the impairment are different for each individual patient, some features 
can be commonly observed. For example, the first symptoms to appear are episodic memory deficits and the related difficulties in remembering recent events. Furthermore, since dementia-affected patients lose the ability to retain and process complex stimuli, they experience an increasing difficulty in making sense of the external world. Any system/technology/support to be successfully integrated in the treatment of dementia should strictly address the following requirements. For example, the gross-motor physical limitations of these patients suggest a limited interaction space populated by objects whose dimensions and weights are suitable for an easy manipulation. Because of the difficulties in making sense of novel and complex situations, it is fundamental to design very simple and clear interaction modalities based on physical and sensorial manipulation. In order to exploit residual abilities related to procedural knowledge, the system should be able to stimulate familiar sensory-motor patterns. Other stimuli should be reduced in order to avoid the dispersion of the limited attention span of patients. Due to the difficulties that patients affected by dementia have with verbal communications, the system should sustain non-verbal dialogues (Marti and Giusti 2007).

In parallel with the observation and the study of clinical cases and therapeutic practices, a number of creative design sessions were carried out by the design team using the results of the field study as design guidelines. Our approach generated an extraordinary diversity of concepts that were continuously assessed by therapists and physicians. In particular, a multi-sensory environment was developed, enhanced with ambient intelligence technologies. The aim was to obtain an optimal level of stimulation of dementiaaffected patients through the use of lights, smells, images, and interactive tools that were able to stimulate engagement, active participation and intrinsic motivation in a therapeutic (leisure) activity and to favour the emergence of personal meanings (memories, interpretations and narratives). Two kinds of tools have been implemented: Light \& Sound Cylinders and Rolling Pins (Marti et al. 2007). Both tools exploit the patients' residual skills, addressing the motor procedural memory that remains intact the longest. This memory contains sensory-motor patterns that are activated by specific configurations of stimuli. By evoking consolidated sensory-motor patterns, like rolling, grasping, shaking and piling objects one on top of another, patients can start to interact with tools. Natural interaction modalities trigger a behavioural answer and constitute a bridge to engage the patients in meaningful activities that can help to generate an intrinsic motivation to actively participate (Fig. 2).

The therapists became active co-creators of novel activities with the devices and also had many suggestions for tool enhancements. The design process was developed using relatively limited observational studies and participatory design sessions mainly with therapists and carers because of the difficulties and the ethical concerns connected with involving the patients and, in some cases, also the care givers in the design process.

The problem of the limited expressivity of our users was dealt with by adopting a co-evolutionary approach intertwining cycles in which user-driven and design-driven development were conducted in parallel, intersecting them frequently to compare the results and re-tune the process. Our stakeholders, mainly therapists and geriatrics, were constantly involved in the process even if a pure creative phase of concept generation was
Fig. 2 Left A trail with rolling pins; right a trial with light and sound cylinders

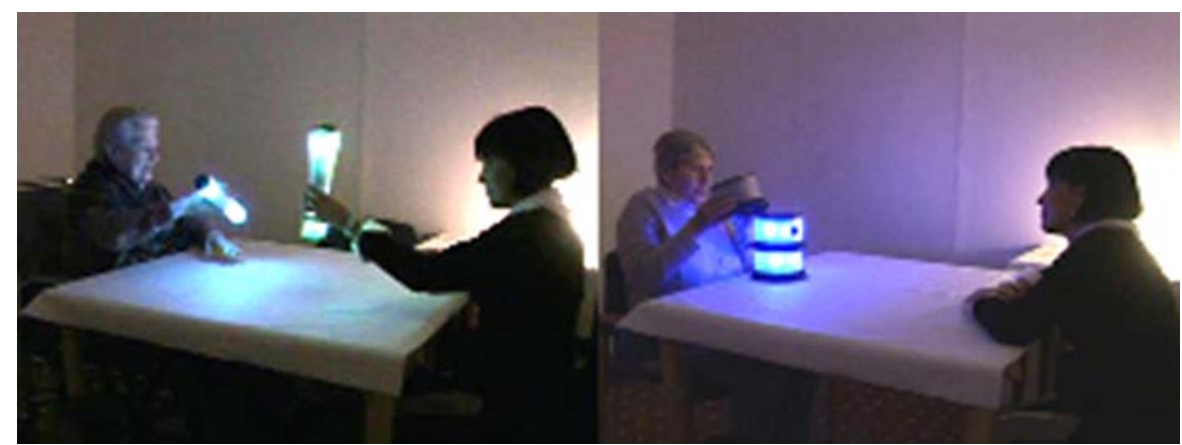


carried out independently by the design team and within the design team ${ }^{2}$.

\section{The Multiple Modes of Participation in UCD}

We have noted the evolution of the concept of UCD over the years. In early HCI-related studies, the meaning of "participation" was often limited, being more a case of "consultation" than active participa$\operatorname{tion}^{3}$. More recently, there have been increased efforts at engaging with users in the problem setting and concept generating phases of design, as active actors and members of the design team. Thus, the role of users shifts from that of simply being informants and testers to being co-designers. One must also note that there are many different forms of design projects, from time-critical commercial product-oriented projects to more exploratory design research exercises, more focused on process, and these allow for differing levels and forms of end-user involvement. Attempting to work with users as full co-designers can be problematic for certain projects. Problems can range from a paucity of user skills necessary to engage in a meaningful way with the design team, both at the level of design skills, e.g. brainstorming and sketching ideas, to articulating and communicating their concepts with the design group and at the level of project management - involving such banal issues as securing sufficient time away from their regular activities to engage meaningfully in the design activities required.

The acceptance of the need for user involvement and the assumption that user participation at all stages in the design process is desirable are two of the mantras of the current HCI community. Nonetheless, there are occasional voices raised that question this way of thinking. For example, Webb (1996) argues that, in certain circumstances, user involvement may be neither feasible nor desirable: "not feasible because the design environment is new, innovative, creative

\footnotetext{
${ }^{2}$ Indeed, advocacy of designer-led activities for part of the design cycle, intertwined with joint user-designer experimentation, is persuasively argued in the paper by Agostini et al. (2000) on "user seduction".

${ }^{3}$ While there are subtle distinctions between the usage of the terms "user involvement" and "user participation", with the latter often connoting a more active engagement in the process, we will use the terms synonymously in this paper.
}

and dynamic and users are heterogeneous and difficult to access. Not desirable because user involvement itself may constrain creativity" (Webb 1996). Webb looks favorably on the list of problems that can accrue in attempting to engage users in the design process, citing Woolgar (1994): "users don't know what they need; users don't know what is good for them; users cannot properly articulate their needs, even when they do know them; users change their minds; users say different things to different people; users disagree with other users about what they need; users may not be real users at all" (Webb 1996). Each of these statements is worthy of extensive debate, which we do not have time for this study, but it at last should raise our awareness of some potential difficulties. Gulliksen et al. (2003) refers to the critique of Constantine and Lockwood (2002) that "User studies can easily confuse what users want with what they truly need. Rapid iterative prototyping can often be a sloppy substitute for thoughtful and systematic design." Let us examine in some more detail a few critical issues regarding the role of users and how and why their role may not be quite as all-encompassing in the design process as is often advocated in the HCI community. We enumerate these possible difficulties below:

\section{The Problem of "Users as Designers"}

While there is a sense in which all users can be viewed as designers at some level - in terms of being able to have some ideas as to how to think creatively about new tools and uses - it is, of course, not the case that most users have the design skills necessary to play a positive role in all stages of the design process. Concept creation can be especially problematic. It is much easier to see a role for users in discussing their requirements and testing and exploring early prototypes. Of course, there is room for forms of engagement that can encourage and elicit useful user input in many aspects of design, but integrating users into certain design practices can be difficult, especially in situations where users may have certain fixed views on what is required, which may be difficult to incorporate into the design team's overall aesthetic design.

\section{The Problem of (Consumer) Product Development}

The kind of bespoke information systems developed in early participative design projects differ markedly from 
the kind of commercial environments in which much consumer product design is done in today's world. Indeed, identifying the user population ahead of time is not always so easy, and in any event, solutions are often driven by the availability of new technologies, existing product lines and market strategies. In this context, users are often involved, if at all, quite late in the development process (Grudin 1991).

The Problem of Comprehending New Technological Infrastructures and Ecologies

New kinds of pervasive sensor-based and embedded technologies require a very different understanding than traditional user-interface design activities. In this framework, users need to understand and control the composition of different system elements and also be able to make sense of them. They need to be aware of technological solutions on the logical level (what can be done with this, what can go together with what and for what purpose), the functional level (how to use it) and on the physical level (it must be possible to see what fits together and to actually build/rebuild). In this context, full participation in the design process may be very difficult for users.

\section{The Problem of Limited User Expressivity in Certain} Domains

Another aspect is related to the application domain. In specific domains like health care or rehabilitation, users are individuals whose temporary or permanent impairments may limit the degree to which they can collaborate or express themselves appropriately. In such cases, traditional participatory design practices can be simply inappropriate or unethical, since discussion, sharing and negotiation between users and designers can create confusion or upset for the user group.

\section{The Problem of Working With a Multi-Faceted Design Team}

A final factor that may limit the role of users in the design process is the composition of the design team. If the design team is composed of professional designers with skills in interaction, visual, graphical and product design, the involvement of the users will tend to be postponed in the process and to be focused on specific phases like requirement elicitation, scenario definition and iterative assessment. If the design team is made up of researchers in HCI, then more users can be involved early in the process and, in particular, in creative sessions to develop the vision of the project.

\section{Concluding Remarks}

Our purpose in noting some of the potential difficulties with UCD strategies is not to question the general approach, as we very much agree with it, from both a pragmatic, functional, ethical and political viewpoint, but to raise awareness as to the potential difficulties that may occur and argue for a more nuanced approach to the practical implementation of such a strategy. Furthermore, we highlighted, through the presentations of real projects, important issues about user participation, such as the importance of considering ethics and values in UCD and technology development. As Scaife et al. (1997) state, "the real issue would seem, therefore, to be not one of whether involving users is good or bad but rather how to more effectively engage them in the design process." User participation should always be regarded as a value; it should be tailored to the knowledge and the abilities of people involved in the design process. Users need to be prepared for playing their role effectively, for contributing with their domain knowledge to the project, for defining concepts, for evaluating and comparing solutions and identifying usage problems according to their abilities and possibilities to participate in the design process. We welcome and encourage a more widespread discussion from HCI researchers, interaction designers, and all interested parties, as to how we can ensure as open and participative a design process as is possible in any given set of circumstances.

\section{References}

Agostini, A., De Michelis, G. and Susani, M. (2000) "From User Participation to User Seduction in the Design of Innovative User-Centered Systems. In R. Dieng, et al. (Eds.), Designing Cooperative Systems: The Use of Theories and Models. Proc. of the 5th International Conference on the Design of Cooperative Systems (COOP'2000, Sophia Antipolis, France, May 2000), IOS Press, pp. 225-240.

Bjerknes, G., P. Ehn, \& M. Kyng (Eds.) (1987), Computers and democracy - a Scandinavian challenge, Aldershot, UK: Avebury. 
Boehm, B. (1988) The spiral model of software development and enhancement. IEEE Computer, 21(5): 61-72.

Constantine, L. L. and Lockwood, L. A. D. (2002), User-Centered Engineering for Web Applications. IEEE Software, 19(2), $42-50$.

Cooper, A. (1999) The inmates are running the asylum: Why high-tech products drives us crazy and how to restore the sanity (Indianapolis, Indiana: SAMS).

Crabtree, A., Hemmings, T., Rodden, T., Cheverst, K., Clarke, K., Dewsbury, G., Hughes, J. A. and Rouncefield, M. (2003) Designing with care: Adapting cultural probes to inform design in sensitive settings. Proc. OZCHI 2003, University of Queensland, 4-13.

Domus Academy (1999). Concept design. POGO deliverable no. $99007 / \mathrm{v} .1$.

Druin, A. (Ed.) (1998). The Design of Children's Technology: How we design and why? San Francisco (CA): Morgan Kaufmann.

Ehn, P., and Kyng, M. (1987). The Collective Resource Approach to Systems Design. In G. Bjerknes, P. Ehn, \& M. Kyng (Eds.), Computers and democracy - a Scandinavian challenge, (pp. 17-58). Aldershot, UK: Avebury.

Erdmann, R.L. and Neal, A.S. (1971) Laboratory vs. field experimentation in human factors. An evaluation of an experimental self-service airline ticket vendor. Human Factors, 13, 521-531.

Gould, J. D., \& Lewis, C. (1985). Designing for usability: Key principles and what designers think. Communications of the ACM, 28, 3, 300-311.

Gould, J. D., Boies, S. J. and Ukelson, J. (1997), How to Design Usable Systems. In M. Helander, T. K. Landauer and P. Prabhu (eds) Handbook of Human-Computer Interaction (Amsterdam: Elsevier Science B.V).

Greenbaum, J. and Kyng, M. (1991), Design at Work: Cooperative Design of Computer Systems, Hillsdale, NJ: Lawrence Erlbaum Associates.

Grudin, Jonathan (1991): Obstacles to User Involvement in Software Product Development, with Implications for CSCW. International Journal of Man-Machine Studies, 34 (3), 435-452.

Gulliksen, J. Goransson, B., Boivie, I., Blomkvist, S. Persson, J, Cajander, Å., (2003), Key principles for user-centred systems design. Behaviour \& Information Technology, 22 (6), 397-409.

ISO 13407. 1999, Human-centered design processes for interactive system (Geneve: International Organization for Standardization).
Kapor, M. (1990) A Software Design Manifesto (reprinted in Terry Winograd (ed.) Bringing Design To Software, Addison-Wesley, 1996), 1-9.

Kyng, M. (1995) Making Representations Work. Communications of the ACM, 38(9), 46-55.

Marti, P., Lund, H.H., Bacigalupo, M. Giusti, L., Mennecozzi, C. (2007), Blending Senses: A Multi-sensory Environment for the treatment of Dementia Affected Subjects, Journal of Gerontechnology, 6(1), 33-41 ISSN 1569-1101.

Marti, P. Giusti, L. (2008), Crafting Sensorial Stimulation and Social Exchange in Dementia Care. The 6th International Conference of the Gerontechnology, June 4-7, 2008Pisa, Italy.

Marti, P. Giusti, L. (2007), Coupling the digital and the physical: a way on in the design of tangible media, In Human-Computer Interaction. Interaction Platforms and Techniques. Volume 4551/2007 12th International Conference, HCI International 2007, Beijing, China, July 22-27, 2007, Proceedings, Part II. ISSN0302-9743 (Print) 1611-3349 (Online), pp 1173-1182. Berlin: Springer/ Heidelberg.

Nielsen, J. 1993, Usability Engineering, Cambridge, MA: AP Professional.

Norman, D. A., Draper, S. W. (eds) (1986). User Centred Systems Design. Hillsdale, NJ: Lawrence Erlbaum Associates Inc.

Ripich, D.N., Vertes, D., Whitehouse, P., Fulton, S., Ekelman, B. (1991) Turn-taking and speech act patterns in the discourse of senile dementia of the Alzheimer's type patients. Brain Lang, 40(3):330-343.

Rizzo, A. Marti, P. Decortis, F., Moderini, C., Rutgers, J. (2003), The design of POGO world, In Hollnagen E. (ed.) Handbook of Cognitive Task Design, New Jersey: Erlbaum, 577-602.

Scaife, M. Rogers, Y. Aldrich, F. Davies, M. (1997) Designing For or Designing With? Informant Design For Interactive Learning Environments. Proceedings of CHI 97, 22-27 March 1997, Atlanta, USA, 343-350.

Webb, B.R, (1996) The role of users in interactive systems design: when computers are theatre, do we want the audience to write the script? Behaviour and Information Technology, 15, 2, 76-83.

Woolgar, S. (1994), Rethinking requirements analysis: some implications of recent research into producer-consumer relationships in IT development, in M. Jirotka and J. Goguen (eds), Requirements Engineering: Social and Technical Issues. London: Academic, 201-216. 